[Contributions from the Research Laboratory of Physical Chemistry of the MassachusetTS INSTITUTE OF TEChNOLOGY, No. 22.]

\title{
THE CONDUCTIVITY AND IONIZATION OF SALTS, ACIDS, AND BASES IN AQUEOUS SOLUTIONS AT HIGH TEMPERATURES.
}

A Report by ARthur A. Noxes upon a Series of Investigations by A. A. NOYEs, A. C. MELCHER, H. C. Cooper, G. W. Eastman and Yogoro Kato.

In a previous paper ${ }^{1}$ from this laboratory by A. A. Noyes and W. D. Coolidge an apparatus and method were described for the accurate measurement of the electrical conductivity of aqueous solutions at high temperatures. Measurements with solutions of potassium and sodium chlorides were presented and discussed. Further measurements have since been made with these two salts, and the investigation has been extended to other di-ionic salts (silver nitrate, magnesium sulphate, sodium acetate, ammonium chloride, and ammonium acetate), to two tri-ionic salts (barium nitrate and potassium sulphate), to an acid salt (potassium hydrogen sulphate), to certain acids (hydrochloric, nitric, sulphuric, phosphoric and acetic acids), and to certain bases (sodium, barium, and ammonium hydroxides). With most of these substances the measurements have been made at four or more different concentrations varying between 0.1 and 0.002 normal and at temperatures ranging from $18^{\circ}$ to $306^{\circ}$.

For the original data and for a detailed description of the experimental methods and of the calculations, reference should be made to Publication No. 63 of the Carnegie Institution of Washington, of a part of which publication this article is a brief summary. ${ }^{2}$ Only the final results will be communicated here.

Tables I and 2 contain the values of the equivalent conductance of the various substances expressed in reciprocal ohms. The values of the concentration given in the second column express the milli-equivalents of solute per liter of solution at the temperature to which the conductance value refers. (In the two cases of potassium hydrogen sulphate and phosphoric acid, however, the concentration is expressed in milli-formulaweights of solute $\left(\mathrm{KHSO}_{4}\right.$ or $\left.\mathrm{H}_{3} \mathrm{PO}_{4}\right)$ per liter of solution, and the values are correspondingly the molal (or "formal") conductances instead of the equivalent conductances). In obtaining these values excepting, however, the cases of the strong acids, the conductance of the water was subtracted, and those for sodium acetate, ammonium acetate, and ammonium chloride have been corrected for the effect of the hydrolysis of the salts. The atomic weights employed were those given by the International Commission for I905, referred to oxygen as 16.00 . The temperature is the

1 This Journal, 26, 134-170 (1904).

${ }^{2}$ Copies of that publication may be obtained at a cost of $\$ 2.50$ each, by application to the authorities of the Carnegie Institution. 


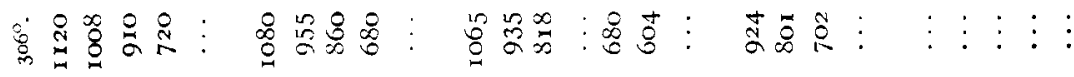

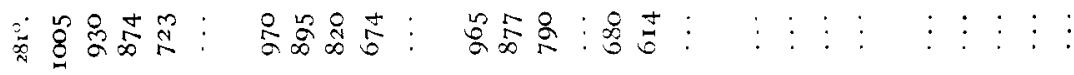

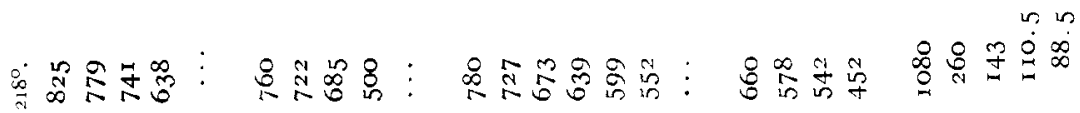

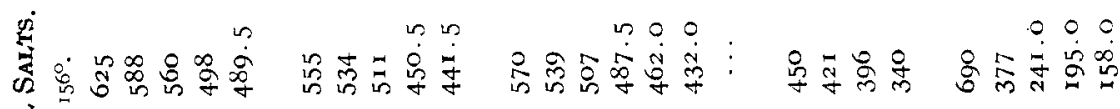
焉

产

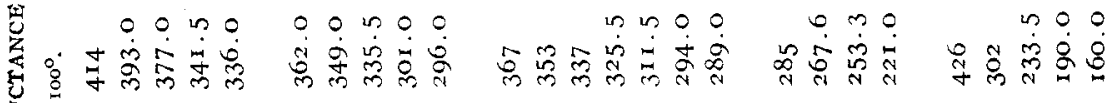
惫 .

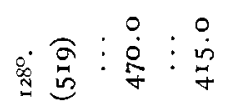
: 鼠

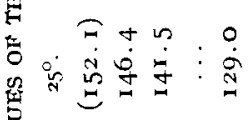

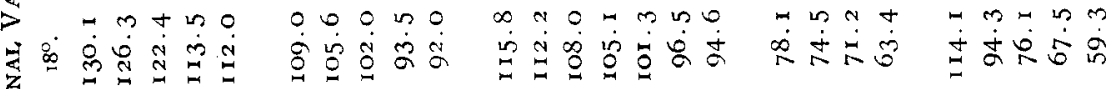
F

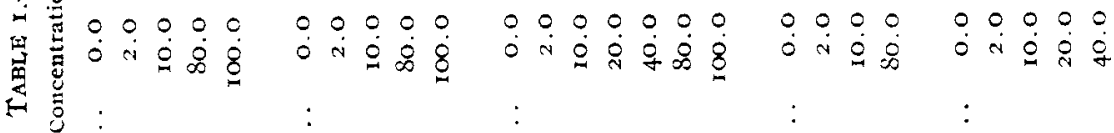

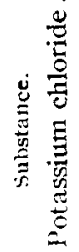




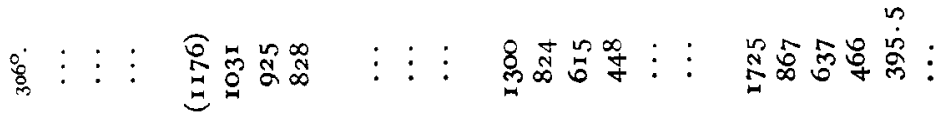

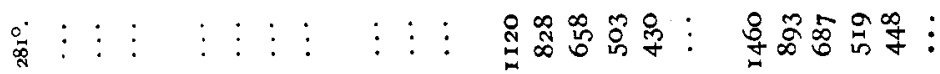

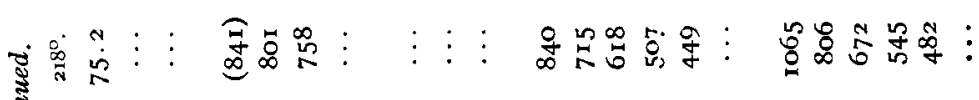

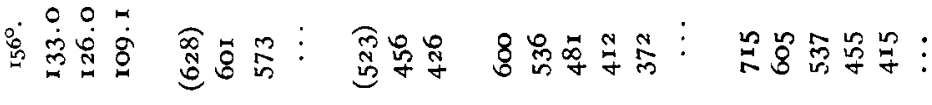

\&:

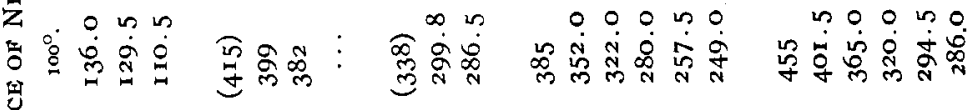

要

然

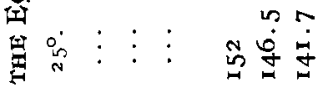

5

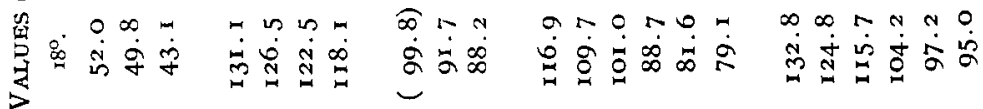

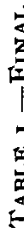

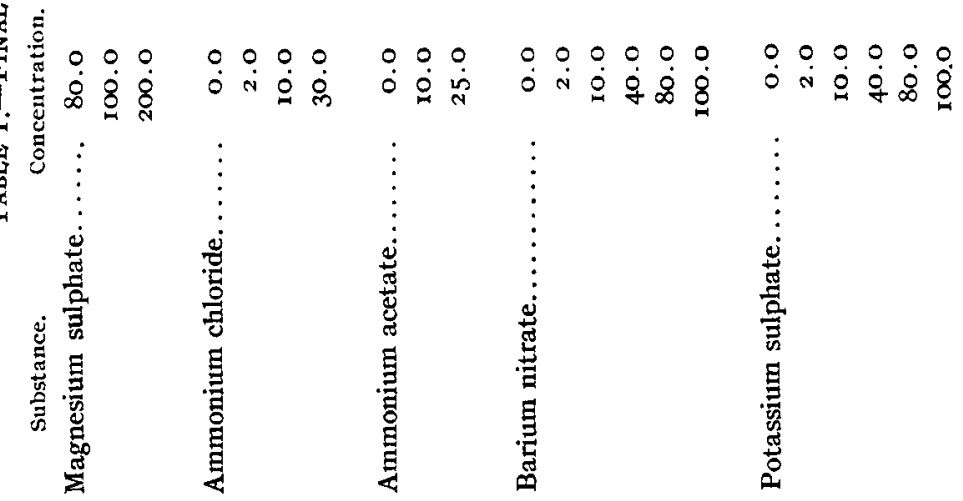




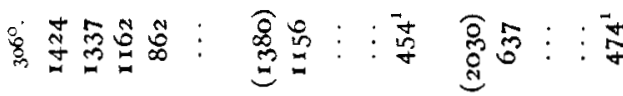

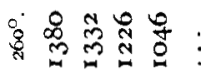

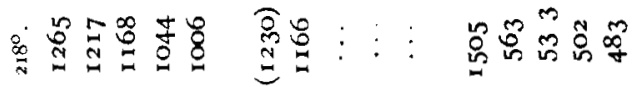

20

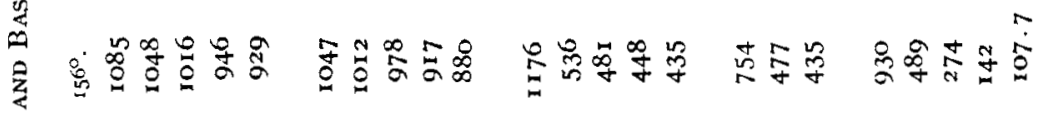

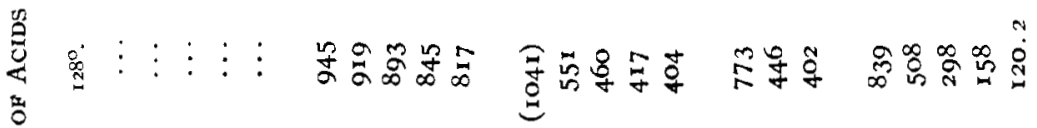
ช

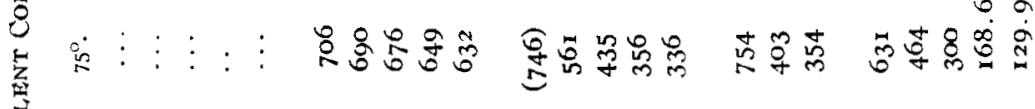

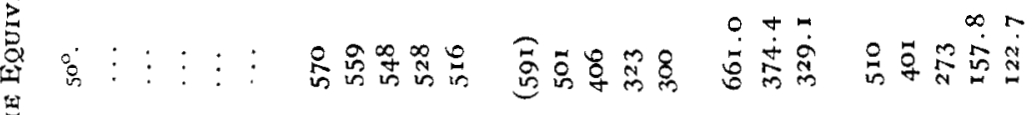

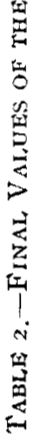

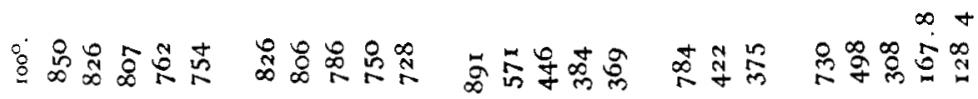

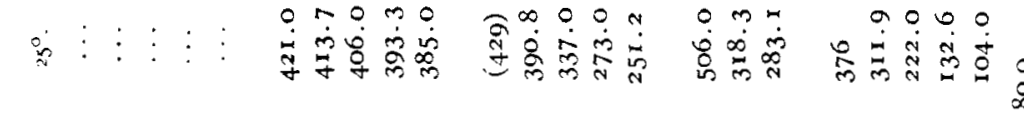

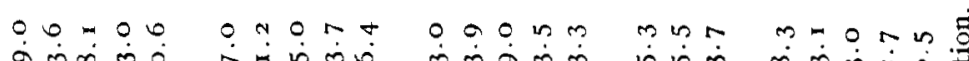

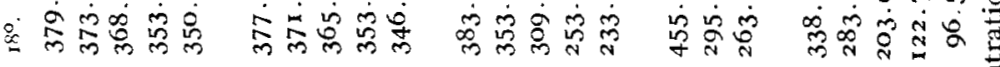

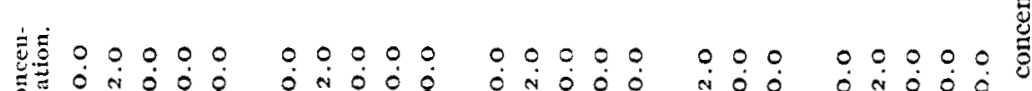
夏

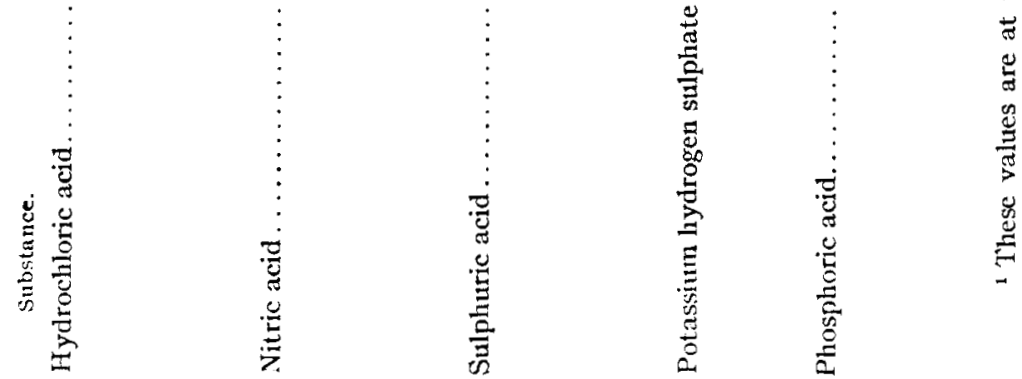


SALTS, ACIDS AND BASES.

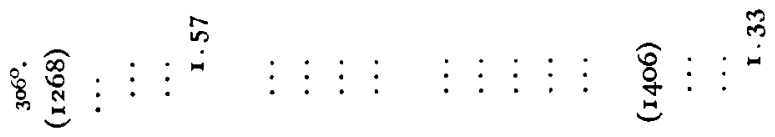

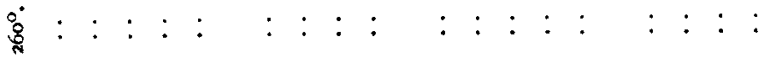

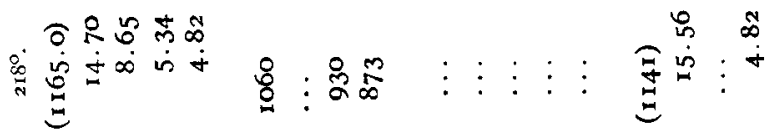

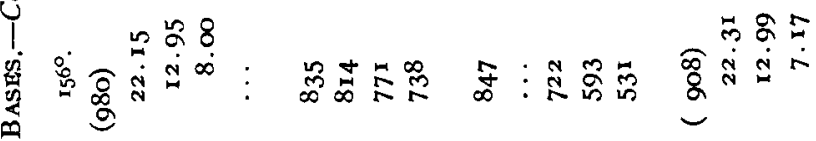

量

ข

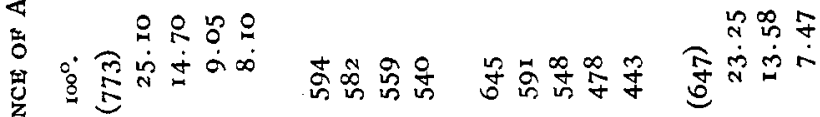

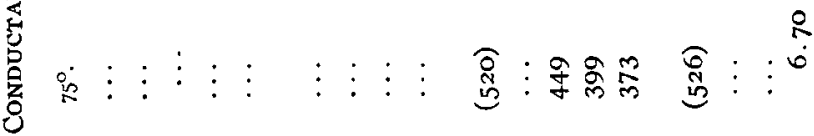

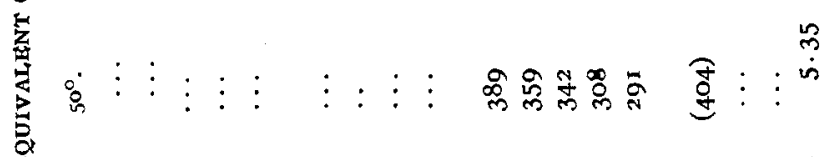

署

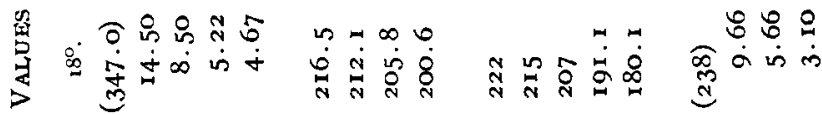

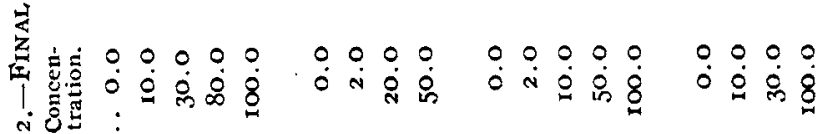

窟

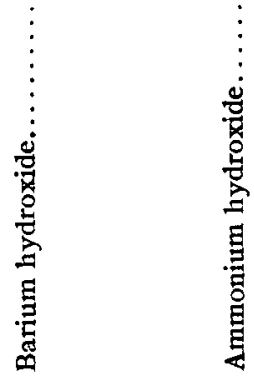


true temperature on the hydrogen-gas scale (as derived at the higher temperatures from the determinations of Jaquerod and Wassmer ${ }^{1}$ of the boiling-points of naphthalene and benzophenone). The conductance values $\left(\Lambda_{0}\right)$ at zero concentration were mostly obtained with the help of an empirical function of the form $\mathrm{I} / A_{0}=\mathrm{I} / A-K(C A)^{n-1}$, which corresponds to the equation $C\left(\Lambda_{0}-\Lambda\right)=K(C A)^{n}$, by plotting the reciprocal of the equivalent conductance $(I / \Lambda)$ at the various concentrations (C) against $(C A)^{n-1}$, varying the value of $n$ till a linear plot was obtained, and then extrapolating for zero concentration. For the slightly ionized substances and for some of the others the $\Lambda_{0}$ values were derived from the others by the principle of the additivity of ion conductances; and in a few cases, the values at certain intermediate temperatures were obtained by graphic interpolation; values derived in either of these ways are indicated by enclosure within parentheses.

These conductivity results have interest from a theoretical standpoint mainly in two respects-first, with reference to the equivalent conductance of the ions or their specific migration-velocities; and second, with reference to the degree of ionization of the various substances.

The directly derived values of $A_{0}$ for the largely ionized electrolytes are summarized in the following table. The substances are arranged primarily according to the ionic type and secondarily in the order in which the $A_{0}$ values at $18^{\circ}$ increase. In adjoining columns are given also the mean temperature-coefficient $\Delta A_{0} / \Delta t$ for the successive temperature-intervals and the ratio $A_{0(\mathrm{~s})} / A_{0(\mathrm{KCl})}$ of the equivalent conductance of the substance in question to that of potassium chloride at the same temperature.

The results given under $A_{\mathrm{o}(\mathrm{s})} / \Lambda_{\mathrm{o}(\mathrm{KCl})}$ in Table 3 show that the values of the equivalent conductance for complete ionization in the case of all the di-ionic substances investigated become more nearly equal as the temperature rises, the approach toward equality being rapid between $18^{\circ}$ and $218^{\circ}$, but comparatively slow at the higher temperatures. This shows, of course, that the specific migration-velocities of the ions are themselves more nearly equal, the higher the temperature. Complete equality has not, however, been reached even at $306^{\circ}$, but the divergence exceeds 5 per cent. only in the cases of hydrochloric acid, sodium hydroxide, and sodium acetate, which have ions which at $18^{\circ}$ move with exceptionally large or small velocities.

The behavior of the tri-ionic salts, potassium sulphate and barium nitrate, is especially noteworthy. Their equivalent conductance increases steadily with rising temperature and attains values which are much greater than those for any di-ionic uni-univalent salt. Thus, at $306^{\circ}$, the value for potassium sulphate is about 1.5 times as great as that for

${ }^{1} \mathrm{~J}$. chim. phys., 2, 72 (1904). 
Table 3.-Egutvalent Conductance at Z Z ERo Concentration.

\begin{tabular}{|c|c|c|c|c|c|c|c|c|c|}
\hline \multirow{3}{*}{$\begin{array}{l}\text { Temper- } \\
\text { ature. }\end{array}$} & \multicolumn{3}{|c|}{ Sodium acetate. } & \multicolumn{3}{|c|}{ Sodium chloride. } & \multicolumn{3}{|c|}{ Silver ritrate. } \\
\hline & & $\underline{\Delta \Lambda_{0}}$ & $\Lambda_{0}(S)$ & & $\Delta \Lambda_{0}$ & $\Lambda_{\mathrm{o}}(\mathrm{s})$ & & $\Delta \Lambda_{0}$ & $\Delta_{0}(\mathrm{~S})$ \\
\hline & so. & $\overline{\Delta t}$. & $\overline{\Lambda_{0}(\mathrm{KCl})}$. & $\Lambda_{0}$. & $\overline{\Delta t}$. & $\overline{\Lambda_{0}(\overline{\mathrm{KCl}})}$ & $\Lambda_{0}$. & $\Delta t$ & $\overline{\Lambda_{0}(\mathrm{KCl})}$. \\
\hline 18 & 78.1 & & 0.60 & 109.0 & & 0.84 & II 5.8 & & 0.89 \\
\hline & & 2.53 & & & 3.09 & & & 3.06 & \\
\hline 100 & 285 & & 0.69 & 362 & & 0.87 & 367 & & 0.89 \\
\hline & & 2.95 & & & $3 \cdot 44$ & & & 3.62 & \\
\hline 156 & 450 & & 0.72 & 555 & & 0.89 & 570 & & 0.91 \\
\hline & & 3.40 & & & $3 \cdot 3 I$ & & & $3 \cdot 39$ & \\
\hline 218 & 660 & & 0.80 & 760 & & 0.92 & 780 & & 0.95 \\
\hline $28 \mathrm{I}$ & .. & 3.00 & . & 970 & $3 \cdot 33$ & 0.96 & 965 & 2.94 & 0.96 \\
\hline
\end{tabular}
$306 \quad 924$
$0.82 \quad 1080$
$4 \cdot 40$
4.00
0.95
$0.96 \quad 1065$

\section{Potassium chloride.}

$$
18
$$$$
\text { I30. I }
$$$$
3.46
$$

$100 \quad 414$

$$
3 \cdot 77
$$

I $56 \quad 625$

$218 \quad 825$

$$
2.86
$$

\section{Ammonium chloride.}

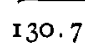

Sodium hydroxide.

$\begin{array}{lccccc}\text { I30.7 } & & \text { I.OI } & 216.5 & & \text { I.67 } \\ 415 & 3.47 & & . & 4.60 & \\ 628 & 3.80 & 1.00 & 594 & & \text { I. } 43 \\ & 3.43 & 1.00 & 835 & 4.30 & \\ 84 I & & 1.02 & 1060 & & 1.33\end{array}$

I.05
$281 \quad 1005$

4.60

$306 \quad$ I 120

$$
\text { .. } \quad \text { I } 76
$$

$18 \quad 116.9$ 3.27

$100 \quad 385$

$$
3.84
$$

I56 600

$218 \quad 840$

3.87

0.90

$0.96 \quad 715$

$$
4 \cdot 44
$$

$28 I$ II 20

7.20

$306 \quad 1300$

Phosphoric acid.

$$
\text { I8 }
$$$$
338
$$

$$
3.81
$$

0.93$$
\text { I.02 } 1065
$$

$\frac{\text { Pota }}{132.8}$

Barium hydroxide.

$\overbrace{222}^{\text {Barium hydo roxide. }}$

$3 \cdot 93$

I. 02

I. IO 645

$3 \cdot 58$

I. 56

4.64

I. $14 \quad 847$

I. 36

5.64

6.27

I. II 1460

I0. 6

I. 29

I. 45

I. 54

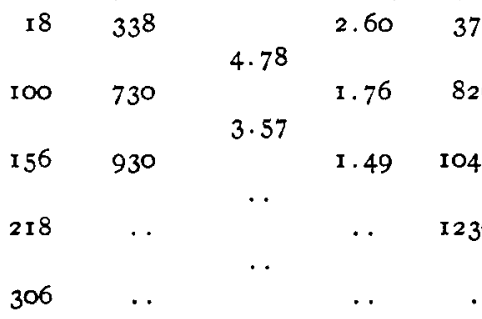

$\overbrace{377 \quad \text { Nitric acid. }}^{1725}$

377

$5.6 \pi$

$3 \cdot 95$

2.90

1.99 I. $67 \quad 1085$

2.95
850

Hydrochloric acid.

\begin{tabular}{rrr}
\hline 379 & & 2.91 \\
850 & 5.76 & \\
1085 & 4.20 & 2.05 \\
1265 & 2.90 & 1.73 \\
1424 & 1.81 & 1.53 \\
& & 1.27
\end{tabular}


potassium chloride. This behavior, which at first sight appears abnormal, is in reality in conformity with the principle that the velocities of ions subjected to the same electric force approach equality with rising temperature; for, assuming that the resistance of the medium becomes the same for all ions, the velocity of a bivalent ion, owing to its double electric charge, should become twice as great as that of a univalent ion under the same potential-gradient; and correspondingly, the equivalent conductance of a completely ionized uni-bivalent salt should become I.5 times that of a completely ionized uni-univalent salt. What is remarkable is, therefore, not the greater values at high temperatures, but the approximate equality at room temperature of the equivalent conductances of bivalent and quivalent ions, especially of the clencintary ones which might be expected to have not far from the same size. This equality may be due, as has been suggested by Morgan and Kanolt, ${ }^{1}$ to a relatively large hydration of the bivalent ions.

With respect to the form of the temperature-conductance curve, it will be seen from an examination of the values of $\Delta A_{0} / \Delta t$ that the rate of increase of conductance is in case of all the neutral di-ionic salts greater between $100^{\circ}$ and $15^{\circ}$ than it is between $18^{\circ}$ and $100^{\circ}$, or between $156^{\circ}$ and $218^{\circ},{ }^{2}$ and, therefore, that the curve is first convex, later concave, and then again convex toward the temperature axis, with two intermediate points of inflexion.

In the case of acids and bases, however, and therefore hydrogen-ion and hydroxide-ion, the rate of increase of the equivalent conductance steadily decreases with rising temperature, so that the curve is always concave toward the temperature axis. With the tri-ionic salts, on the other hand, the rate of increase steadily increases, owing to the great increase in the equivalent conductance of the bivalent ion; the curre is therefore always convex toward the temperature axis.

It is of interest to note that the fuidity, or the reciprocal of the viscosity, of water shows nearly the same increase as the conductance of the di-ionic salts, at any rate up to $156^{\circ}$, which is about the limit to which previous deterninations of the viscosity have extended. 'Thus, using for the viscosity $(\eta)$ the data of Thorpe and Rodger and of de Haas ${ }^{3}$ and taking the mean values of $A_{0}$ for the five uni-univalent salts included in this research, the product $\eta \Lambda_{0}$ has the values I. I9 at $18^{\circ}, 1.04$ at $100^{\circ}$, and $\mathrm{I} . \mathrm{O}$ at $156^{\circ}$. When it is considered that the conductance values

'This Journal, 28, 572 (1906).

${ }^{2}$ With respect to this last temperature-interval sodium acetate forms an exception.

${ }^{3}$ See Landolt-Börnstein-Meyerhoffer, Physikalisch-chemische Tabellen, pp. 76-77. From the data there given the viscosity in dynes per sq. $\mathrm{cm}$. is found by interpolation to be $0.0105^{2}$ at $18^{\circ}, 0.00283$ at $100^{\circ}$, and 0.001785 at $156^{\circ}$. The mean values of $\Lambda_{0}$ for the salts referred to are i 3 at $18^{\circ}, 369$ at $100^{\circ}$, and 566 at $156^{\circ}$; the salts investigated were potassium, sodium and ammonium clilorides, sodium acetate and silver-nitrate. 
increase five-fold, this variation in the ratio will be seen to be of secondary significance.

With respect to the variation of the equivalent conductance $(A)$ with the concentration $(C)$, it has been found that between the concentrations 0.1 and 0.002 or 0.0005 normal the results of all temperatures with all the salts, both di-ionic and tri-ionic, and also with hydrochloric acid, nitric acid, and sodium hydroxide, are expressed by the function $C\left(\Lambda_{0}-\Lambda\right)$ $=K(C A)^{n}$ provided that to the exponent $n$ a value (varying with the different substances) between I.4O and I.55 is assigned. This is clearly shown by the summary of the $n$ values given in Table 4 . These were

TABle 4.-VAlues of THE EXPONent $n$ IN THE Function $C\left(\Lambda_{0}-\Lambda\right)=K(C \Lambda)^{n}$.

\begin{tabular}{|c|c|c|c|c|c|c|}
\hline Substance. & $18^{\circ}$ & $100^{\circ}$. & $156^{\circ}$. & $218^{\circ}$ & $28 \mathrm{r}^{\circ}$. & $306^{\circ}$. \\
\hline$\ldots \ldots \ldots \ldots \ldots \ldots$ & I. 42 & 1.40 & I. 40 & I. 48 & I. 50 & 1.48 \\
\hline $\mathrm{NaCl} \ldots \ldots \ldots \ldots \ldots \ldots$ & I. 42 & 1.48 & I. 50 & 1.50 & 1.47 & I. 46 \\
\hline $\mathrm{AgNO}_{3} \ldots \ldots \ldots \ldots \ldots$ & I. 53 & 1.52 & I. 50 & I. 50 & I. 52 & I. 52 \\
\hline $\mathrm{NaC}_{2} \mathrm{H}_{2} \mathrm{O}_{2} \ldots \ldots \ldots \ldots$ & I. 45 & I. 45 & I. 42 & I. 36 & $\cdots$ & . \\
\hline $\mathrm{HCl} \ldots \ldots \ldots \ldots \ldots$ & I. 45 & I. 38 & I. 40 & I. 47 & . & . \\
\hline $\mathrm{HNO}_{3} \ldots \ldots \ldots \ldots \ldots$ & I. 43 & I. 45 & I. 45 & $\cdots$ & $\cdots$ & $\cdots$ \\
\hline $\mathrm{NaOH} . . . \ldots \ldots \ldots \ldots$ & I. 50 & I. 50 & I. 50 & $\cdots$ & $\cdots$ & $\cdots$ \\
\hline $\mathrm{Ba}(\mathrm{OH})_{2} \ldots \ldots \ldots \ldots \ldots$ & I. 55 & I. 45 & I. 45 & . & $\cdots$ & $\cdots$ \\
\hline $\mathrm{K}_{2} \mathrm{SO}_{4} \ldots \ldots \ldots \ldots \ldots$ & I. 42 & I. 42 & I. 42 & I. 42 & 1.42 & I. 42 \\
\hline $\mathrm{Ba}\left(\mathrm{NO}_{3}\right)_{2} \ldots \ldots \ldots \ldots$ & I. 50 & I. 50 & 1. 50 & I. 50 & I. 50 & I. 50 \\
\hline $\mathrm{MgSO}_{4} \ldots \ldots \ldots \ldots \ldots$ & I. 43 & $\ldots$ & $\ldots$ & . & $\cdots$ & .. \\
\hline
\end{tabular}

derived by a graphical method (which involved no assumption in regard to the value of $\Lambda_{0}$ ), this being regarded as a third constant to be determined from the data themselves. In general, the value of $n$ could be found within 0.02 or 0.03 units.

It is evident that, if the conductance-ratio $\Lambda / \Lambda_{0}$ can be taken as a measure of the ionization $(\gamma)$, the latter changes with the concentration in the case of all these substances in accordance with an entirely similar exponential law, namely, in accordance with the function $\frac{(C r)^{n}}{C(\mathrm{I}-\gamma)}=$ const., in which $n$ has values varying with different substances only between 1.40 and $\mathrm{I} .55$.

In a previous article ${ }^{1}$ emphasis was laid on the remarkable fact that at ordinary temperatures the form of the functional relation between ionization and concentration is the same for salts of different ionic types. These results show that this is also true at high temperatures, and, moreover, that even the very large variation of temperature here involved and the large consequent change in the character of the solvent affect

${ }^{2}$ Noyes, "The Physical Properties of Aqueous Salt Solutions in Relation to the Ionic Theory," Congress of Arts and Science, St. Louis Exposition, 4, 317 (1904); Technology Quarterly, I7, 300 (1904); Science, 20, 582 (1904); abstract in Z. physik. Chem., 52, 635 . 
only slightly, if at all, the value of the exponent in this purely empirical ralation. Thus an additional confirmation is given to the inportant conclusion that the form of the concentration-function is independent of the number of ions into which the salt dissociates. This seens to show almost conclusively that chenical mass-action has no appreciable influence in determining the equilibrium between the ions and the unionized part of largely dissociated substances. How complete this contradiction with the mass-action law is, is seen when it is recalled that for di-ionic and tri-ionic salts this law requires that the concentration of the un-ionized substance be proportional to the square and cube, respectively, of the concentration of the ions, while the experimental data show that it is proportional to the $3 / 2$ power of that concentration, whatever may be the type of salt.

It has been found by trial that the functions $A_{0}-A=K C^{\frac{1}{3}}$ and $A_{0}-A=K(C A)^{3}$, which contain only two arbitrary constants $\left(A_{0}\right.$ and $\left.K\right)$, also satisfactorily express the results with potassium chloride, sodium chloride, hydrochloric acid, and sodium hydroxide at any rate up to $218^{\circ}$ between the concentrations of 0.1 and 0.002 or 0.0005 normal. Since, however, the data at still smaller concentrations, as determined by Kohlrausch and others at $18^{\circ}$, do not conform to the requirements of these functions, they apparently do not give by extrapolation a correct value of $A_{0}$, and correspondingly the ratio $A / A_{0}$ derived from them is not a true measure of the ionization. It has therefore not seemed worth while to make a study of the applicability of these functions to all the substances investigated.

The cquivalent conductance and ionization of the slightly ionized substances, acetic acid and ammonium hydroxide, on the other hand, change with the concentration at all temperatures, even up to $306^{\circ}$, in accordance with the mass-action law. It is interesting to note that phosphoric acid, an acid of moderate ionization (60 per cent. at $18^{\circ}$ and 29 per cent. at $156^{\circ}$ at o.or normal concentration), has intermediate values of $n$ (I.8I.9), which, however, approach more nearly the theoretical value (2.0) than the empirical one.

In order to show the relations between degree of ionization, the character of the substances, and the temperature, the percentage ionization of all the substances investigated at the different temperatures in 0.08 and $0.0 \mathrm{I}$ normal solution is shown in Table 5. The substances are arranged in the order in which the ionization at $18^{\circ}$ decreases. The values in the caes of sulphuric acid show the percentage of the total hydrogen which exists in the form of hyrogen-ion, without reference to whether it arises through the primary dissociation into $\mathrm{H}$ and $\mathrm{HSO}_{4}^{-}$or the secondary one into $\mathrm{H}$ and $\$ O$ : the ralues are only approximate ones based on an estimate of the relative extent to which these two stages in the disso- 


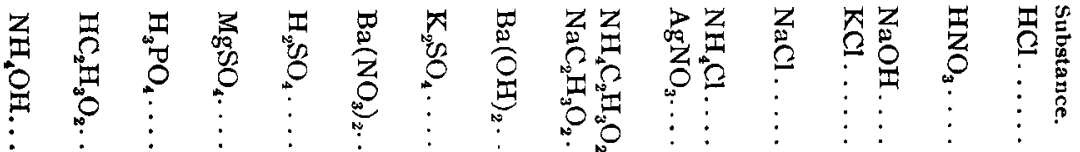

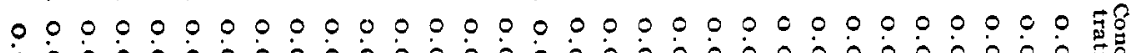

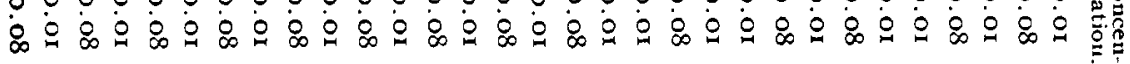

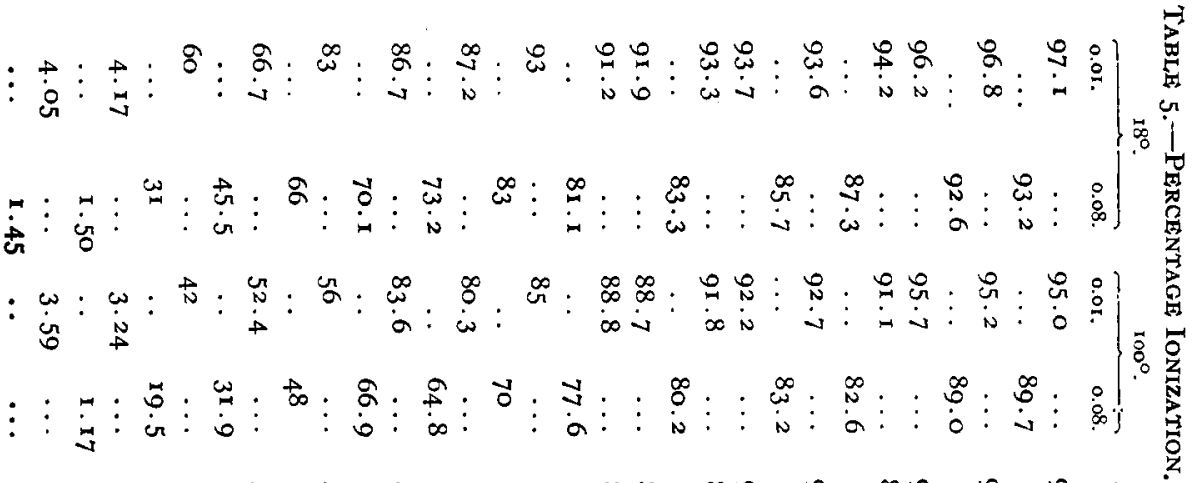

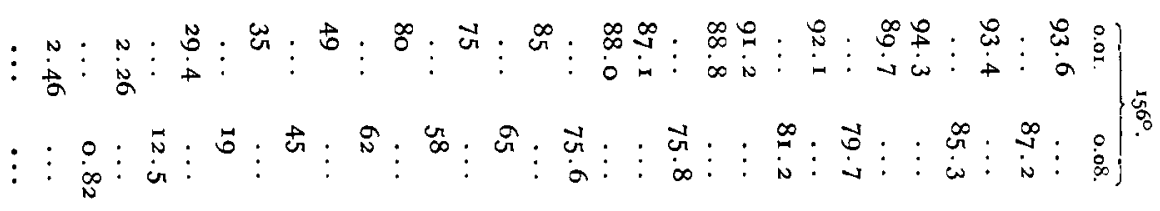

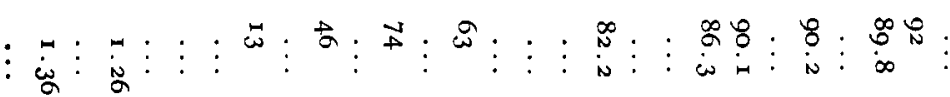

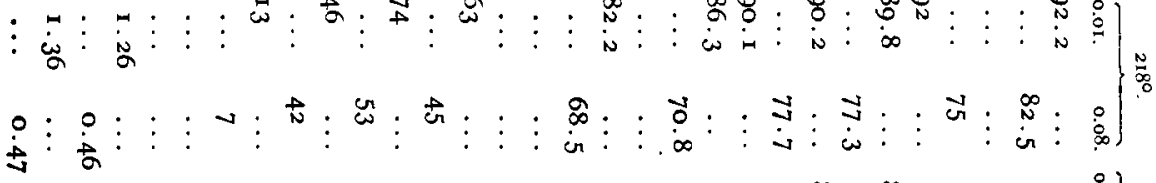

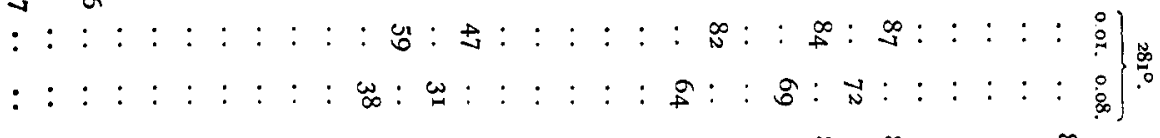
$:::::::::$ : $:$ :

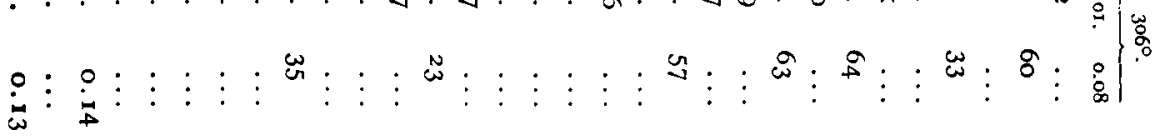


Thus the rate of decrease in ionization is small between $18^{\circ}$ and $100^{\circ}$ for either type of salt; but it becomes greater at the higher temperatures, especially in the case of the tri-ionic salts; and for the highest temperature interval $\left(281^{\circ}-306^{\circ}\right)$ it is extremely rapid for both types of salt. The decrease in ionization of hydrochloric acid, nitric acid up to $156^{\circ}$, and sodium hydroxide is about the same as that of the di-ionic salts; thus the average value of $\left(-\mathrm{IO}^{3} \mathrm{~A} \gamma / \mathrm{At}\right)$ at 0.08 normal for hydrochloric and nitric acids is 0.38 between $18^{\circ}$ and $100^{\circ}, 0.63$ between $100^{\circ}$ and $156^{\circ}$; and for hydrochloric acid 0.76 between $156^{\circ}$ and $218^{\circ}$. Between $156^{\circ}$ and $306^{\circ}$ nitric acid decreases in ionization much more than the other substances of the same type.

The physical property of the solvent which is most closely related to its ionizing power is, as has been shown by Thomson and Nernst, its dielectric constant. It is, therefore, of some interest to compare its variation with the temperature with that of the ionization of salts. Unfortunately, the dielectric constant of water has been determined only between $0^{\circ}$ and $76^{\circ}$. Drude ${ }^{1}$ has, however, derived for this interval a quadratic equation, from which a value at $100^{\circ}$ may be calculated, probably without great error. The values of the dielectric constant obtained from this equation are 81.3 at $18^{\circ}$ and 58.1 at $100^{\circ}$, and the ratios of these is I.40.

The question now arises, what function of the ionization should be compared with this? It seems clear that, from a theoretical standpoint, it is simplest to consider the ratio $\frac{C_{2}}{C_{1}}\left(\frac{\left.I-r_{2}\right)}{\left.I-r_{1}\right)}\right.$ of the concentrations of un-ionized salt which prevail in solutions that at the two temperatures $\left(t_{2}\right.$ and $t_{1}$ ) have the same concentration of the ions (that is, solutions for which $\left.C_{2} \gamma_{2}=C_{1} \gamma_{1}\right)$; for in such solutions the electric force between the ions, and therefore their tendency to unite to form un-ionized molecules, in so far as this has an electrical origin, must be inversely proportional to the dielectric constant. The above ratio is evidently equivalent, since $C_{2} r_{2}=C_{1} r_{1}$ to the ratio $\frac{\left(I-r_{2}\right) / r_{1}}{\left(I-r_{1}\right) / r_{2}}$, where, however, $r_{1}$ and $r_{2}$ refer to the slightly different concentrations $C_{1}$ and $C_{2}\left(C_{2}\right.$ being equal to $\left.C_{1} \gamma_{1} / \gamma_{2}\right)$.

Now for the four uni-univalent salts given in Table 5 the mean values of the percentage ionization at 0.08 normal is 84.4 at $18^{\circ}$ and 80.9 at $100^{\circ}$, or by interpolation, 80.6 at $100^{\circ}$ at $0.08 \times 1.042$ normal (that is, at $\left.C_{1} \gamma_{1} / r_{2}\right)$, whence the value of the ratio just referred to is found to be r.30. The value of the corresponding ratio for the two tri-ionic salts at 0.08 normal is in the same way found to be $1.38 .^{2}$ While the former

${ }^{1}$ Wied. Ann. Phys., 59, 50 (1896).

2 The mean value of the percentage ionization for these two salts at 0.08 normal are 71.7 at $18^{\circ}$ and 65.8 at $100^{\circ}$, or by interpolation 64.8 at $100^{\circ}$ at $0.08 \times 1.09$ normal. 
of these values differs considerably from the ratio (I.4O) of the dielectric constants, yet all the values lie in the same neighborhood. Indeed, the agreement is as close as could be expected, considering the character of the data involved.

Finally, even though it seems theoretically to correspond to a less comparable condition in the solution, yet, in view of the valence principle uedssdisc just below, it is of interest to note the values of the simpler ratio, $\frac{C\left(\mathrm{I}-\gamma_{2}\right)}{C\left(\mathrm{I}-\gamma_{1}\right)}$, of the concentration of the un-ionized substance at two temperatures at the same total concentration, instead of the same ionconcentration. At 0.08 the value of this ratio for $100^{\circ} / \mathrm{I} 8^{\circ}$ is 1.22 for the four uni-univalent, and I.2I for the two uni-bivalent salts, thus considerably less than the ratio of the dielectric constants.

The degree of ionization of the different substances may be next considered in relation to the ionic type to which they belong and to their chemical nature. It has already been pointed out that even up to the highest temperatures neutral salts of the same ionic type have roughly the same percentage ionization, the differences not exceeding 8 per cent. in any case investigated. The strong acids, hydrochloric acid and (up to $15^{\circ}$ ) nitric acid, and the strong bases, sodiun and barium hydroxides, also conform in a general way to this principle, though their ionization seems to be several per cent. greater than that of the corresponding salts; it is worthy of mention, however, that this greater value may be due to an increase in the equivalent conductance of the hydrogen-ion or hydroxide-ion with the concentration of the solute, as is indicated to be the case by the transference results which have been obtained with these acids. ${ }^{1}$

It is also remarkable that the rough proportionality which had previously been shown to exist at ordinary temperatures ${ }^{2}$ between the unionized fraction of a salt at any concentration and the product of the valences of its ions has now been proved to persist up to the highest temperatures, where the degree of ionization has become much less. This is shown by the following summary: Under $A$ are given the mean values of the percentage of un-ionized salt $100(\mathrm{I}-\gamma)$, for the neutral salts of each

\begin{tabular}{|c|c|c|c|c|c|c|c|c|c|c|c|c|c|}
\hline \multirow[b]{2}{*}{$v_{1} \tau_{2}$} & \multirow{2}{*}{$\begin{array}{c}\text { Mols. } \\
\text { per liter. }\end{array}$} & \multicolumn{2}{|c|}{$18^{\circ}$} & \multicolumn{2}{|c|}{$100^{\circ}$. } & \multicolumn{2}{|c|}{$156^{\circ}$} & \multicolumn{2}{|c|}{$218^{\circ}}$. & \multicolumn{2}{|c|}{$281^{\circ}$} & \multicolumn{2}{|c|}{$306^{\circ}$. } \\
\hline & & A. & $B$. & A. & B. & A. & B. & A. & B. & A. & B. & A. & B. \\
\hline $1 \times I$ & 0.04 & I 2 & I 2 & I 5 & I 5 & I 7 & I 7 & 20 & 20 & 25 & 25 & 31 & $3 I$ \\
\hline$I \times I$ & 0.08 & 15 & 15 & I 8 & I 8 & $2 I$ & $2 I$ & 25 & 25 & $3 I$ & $3 I$ & 39 & 39 \\
\hline$I \times 2$ & 0.04 & 28 & 14 & 34 & I 7 & 40 & 20 & $5 \mathrm{I}$ & 25 & 65 & 32 & 74 & 37 \\
\hline $2 \times 2$ & 0.04 & 55 & I 4 & 68 & I 7 & 81 & 20 & 93 & 23 & . & $\ldots$ & . & . \\
\hline
\end{tabular}

1 See This Journal.

2 For a discussion of this principle, see the author's article on "The Physical Properties of Aqueous Salt Solutions," Loc. cit. 
type at the concentration 0.04 molal and for the uni-univalent salts at 0.08 molal; and under $B$ are given the ratios of these values to the product of the valences $\left(v_{1} v_{2}\right)$ of the ions.

It will be seen that the principle continues to hold, especially when the comparison is made at the same equivalent concentration, even when the ionization has become very small; thus it is only 26 per cent. for the uni-bivalent salts at $306^{\circ}$ and only 7 per cent. for the bi-bivalent salt (magnesium sulphate at $218^{\circ}$ ).

The ionization tendencies of phosphoric acid, acetic acid, and ammonium hydroxide, and the effect of temperature on them are best shown by the summary of their ionization-constants which is given in Table $7 .^{1}$ The concentration involved in the constant is expressed in equivalents per liter, and the constants themselves have been multiplied by $\mathrm{IO}^{6}$.

Table 7.-Ionization-Constants of Phosphoric Acid, Acetic Acid, and Ammonium HYDROXIDE.

$\begin{array}{rccc}\text { Temperature. } & \text { Phosphoric acid. } & \text { Acetic acid. } & \text { Ammonium lydroxide. } \\ 0 & \ldots & \ldots & 13.9 \\ 18 & 10400 & 18.2 & 17.2 \\ 25 & 9400 & \ldots & 18.0 \\ 50 & 7000 & \ldots & 18.1 \\ 75 & 4800 & \ldots & 16.4 \\ 100 & 3400 & 11.1 & 13.5 \\ 125 & \ldots & \ldots & 10.4 \\ 128 & 2230 & \ldots . & \ldots \\ 156 & 1420 & 5.42 & 6.28 \\ 218 & \ldots & 1.72 & 1.80 \\ 306 & \ldots & 0.139 & 0.093\end{array}$

It is evident from these results that the ionization-constant for ammonium hydroxide increases considerably in passing from $0^{\circ}$ to $18^{\circ}$, then remains nearly constant up to $50^{\circ}$, and finally decreases with increasing rapidity as higher temperatures are reached, attaining at $306^{\circ}$, a value which is only about one two-hundredth of that at $18^{\circ}$; and that at all temperatures the values for acetic acid are not very different from those for ammonium hydroxide. Phosphoric acid is seen to have a much larger ionization, which, however, decreases steadily and very rapidly with rising temperature.

The interpretation of the results obtained with sulphuric acid is complicated by the fact that the ionization doubtless takes place in two stages; but in the original publication ${ }^{2}$ a method has been described which can only be referred to here, by which it is possible to determine

' In the case of phosphoric acid the values vary considerably with the concentration in correspondence with the fact that the exponent in the concentration-function was found to be I.8-r.9 instead of 2 as required by the mass-action law. The values here given are those at the concentration 0.05 formula-weights $\left(\mathrm{H}_{3} \mathrm{PO}_{4}\right)$ per liter.

${ }^{2}$ Publication No. 6.3 of the Carnegie Institution. D. 27 I. 
the hydrogen-ion concentration within fairly narrow limits from the conductance alone, without knowledge of the extent to which the separate stages occur. The method is of gencral application to dibasic acids; and, if the ionization-constant for the first hydrogen be known, as is true with many of the organic acids, the method could be used for computing that of the second hydrogen from the conductance at high dilutions where the second ionization is appreciable. The ratio of the hydrogen ion to the total hydrogen in the case of sulphuric acid is thus found 10 vary in 0.08 normal solution from about 66 per cent. at $18^{\circ}$ to ${ }^{8}$ at $100^{-}$ and 35 at $306^{\circ}$.

Similar calculations of the hydrogen-ion concentrations have been made in the case of potassium hydrogen sulphate. These show that in o.I molal solution, at $156^{\circ}$, the hydrogen-ion concentration is not more than 3 per cent.; and this justifies the conclusion that the secondary ionization of sulphuric acid (into hydrogen-ion and sulphate-ion) in its own moderately concentrated solutions is also insignificant at this temperature and higher temperatures. Interpreted with the help of this conclusion the conductivity data for the acid show that the primary dissociation (into hydrogen-ion and hydrosulphate-ion) is about the sanle as that of hydrochloric acid at temperatures between $100^{\circ}$ and $306^{\circ}$; and it is reasonable to suppose that the same is true at lower temperatures down to $18^{\circ}$.

With the help of this principle the ionization of the hydrosulphate-ion at $18^{\circ}, 100^{\circ}$, and $156^{\circ}$ in the solutions both of the acid and acid salt has been computed. This ionization is thus found to be large at $18^{\circ}$, but it decreases very rapidly with the temperature. Thus in a 0.1 molal potassium hydrogen sulphate solution equal quantities of sulphate-ion and hydrosulphate-ion are present at $18^{\circ}$, while at $100^{\circ}$ there is only 1.5 per cent., and at $156^{\circ}$ only + per cent., as much sulphate-ion as hydrosulphate-ion in the solution.

Only rough values of the ionization-constant of hydrosulphate-ion into hydrogen-ion and sulphate-ion can be given, since they vary very much with the concentration; some idea of its magnitude is furnished by the following values which hold at about 0.01 molal (or 0.002 nolal at $\left.156^{\circ}\right): 18500 \times 10^{-6}$ at $18^{\circ}, 1220 \times 10^{-6}$ at $100^{\circ}$, and $115 \times 10^{-6}$ at $156^{\circ}$, whereas the ionization-constant of acetic acid at $18^{\circ}$ is 18 $10^{-6}$. I'rom the change of the ionization-constant with the temperature, the heat absorbed $(\Delta E)$ by the reaction $\mathrm{HSO}_{4}^{-}-\mathrm{H}^{-}-\mathrm{SO}_{4}$ has been found to be given by the expression: $\Delta E=14,170--65 \mathrm{~T}$, where $T$ repre sents the absolute temperature. From this it follows that the value at $18^{\circ}$ is -7450 calories, and at $100^{\circ}-10,070$ calories, while from Thom sen's heat-of-neutralization measurements and our ionization data at $1 x^{\circ}$ the valu1 ${ }^{2}$. anan calories is derived. 


\section{Conclusion.}

In the preceding paragraphs have been summarized the generalizations to be drawn from the results of these investigations, in regard to the behavior of the varous types of chemical substances in aqueous solutions through a wide range of temperature. In conclusion, it seems, however, desirable to draw attention again to a theoretical principle of even more general import, which has been already presented in a previous article by the author as a conclusion apparently justified by a study of the then existing data, for this principle has now received a further confirmation through the demonstration of the fact that certain purely empirical laws relating to the ionization of salts in water still continue to be valid, even when the physical condition of that solvent is greatly altered by a large change in its temperature. This principle is that the ionization of salts, strong acids, and bases is a phenomenon primarily determined not by specific chemical affinities, but by electrical forces arising from the charges on the ions; that it is not affected (except in a secondary degree) by chemical mass action, but is regulated by certain general, comparatively simple laws, fairly well established empirically, but of unknown theoretical significance; and that, therefore, it is a phenomenon quite distinct in almost all its respects from the phenomenon of dissociation ordinarily exhibited by chemical substances, including that of the ionization of weak acids and bases.

The most important facts leading to this conclusion are the approximate identity of the ionization values for salts of the same ionic type; the existence of a simple approximate relation between the value of the un-ionized fraction and the product of the valences of the ions; the smal effect of temperature on the ionization of salts and a parallelism between the magnitude of that effect and the effect upon the dielectric constant of water; the validity of an exponential relation between ionization and concentration, which differs from that required by the mass action law, and which is approximately the same at all temperatures and for different ionic types of salts; and the fact that the optical properties and other similar properties of dissolved salts (when referred to equal molal quantities) is independent of this concentration and therefore of their ionization, so long as the solution is even moderately dilute.

The molecular explanation of these facts and the more general conclusions drawn from them would seem to be that primarily the ions are united somewhat loosely in virtue of their electrical attraction to form molecules, the constituents of which still retain their electric charges and therefore, to a great extent, their characteristic power of producing optical effects and such other effects as are not dependent on their existence as separate aggregates. Secondly, the ions may unite in a more intimate wav to form ordinary uncharged molecules. whose constituents have rom- 
pletely lost their identity and original characteristics. These two kinds of molecules may be designated electrical molecules and chemical molecules, respectively, in correspondence with the character of the forces which are assumed to give rise to them. Now in the case of salts and most of the inorganic acids and hases, the tendency to forn chemical molecules is comparatively slight, so that the neutral electrical molecules greatly predoninate. (In the other hand, in the case of most of the organic acids, the tendency to form chemical molecules is very much greater, so that as a rule these predominate. The facts, moreover, indicate that chemical molecules are formed from the ions in accordance with the principle of mass action, ${ }^{1}$ but that electrical molecules are formed in accordance with an entirely distinct principle, whose theoretical basis is not understood.

It is to be expected that with neither class of substances will the predominating type of molecule be alone present; and that minor deviations from the mass action law in the case of moderately ionized substances, and from the usual empirical law in the case of largely ionized substances, may well arise from the presence of a small proportion of molecules of the other type. In the former case, we may indeed with some confidence predict quantitatively that that proportion of electrical molecules will always be present which corresponds for the type of substance in question to the concentration of its ions in the solution.

A fuller expcrimental investigation of the properties of dissolved salts, especially of those of polyionic types, and of the phenomena of the solubility effect and the distribution into a gaseous or another liquid phase of ionizing substances, if combined with a thorough and persistent study of all the available data, gives promise of suggesting a fuller theoretical explanation of this remarkable behavior of largely ionized substances in aqueous solution. Even if such a theoretical interpretation should not be discovered, one may at least hope to determine with greater accuracy and certainty the laws of the cquilibrium between the ions and un-ionized molecules, and between the two forms of the latter, in case their existence shall be more fully substantiated. The facts already known make it almost certain that we have here to deal with a new kind of equilibrium phenomenon, and not simply with some deviation of a secondary nature.

1 The best evidence of this is that furnished by the change of the conductance of slightly ionized electrolytes with the concentration; but distribution experiments also indicate it. Thus it is probable that as a rule the chemical nolecules alone distribute into the gaseous phase or into organic solvents and that therefore the concentration of the substance in such phases is a measure of the concentration of those molecules in the aqueous solution; and the few experiments thus far published indicate that the latter is at least approximately proportional to the product of the concentrations of the ions. (Compare the experiments on picric acid by Rothmund and Drucker, Z. physik. (hem. 46. $826(1002))$. 
a'rising, for example, from a somewhat abnormal osmotic pressure, or a change in the migration velocities of the ions, as has been assumed by most authors.

In conclusion, I desire to express to the authorities of the Carnegie Institution my great indebtedness for the assistance rendered me in the prosecution of these researches; for without such aid little progress could have been made up to the present time.

Boston, December: Igo7.

[CONTRIbution fRom the Laboratory of the Malinckrodt Chemical Works.] THE REFRACTIVE INDICES OF ALCOHOL-WATER MIXTURES. ${ }^{1}$

BY LAUNCELOT W. ANDREWS.

Received January 15, 1908.

To Leach and Lythgoe belong the credit of having first determined, by means of the Zeiss immersion refractometer, the refractive powers of aqueous solutions of methyl and ethyl alcohols and of publishing the results ${ }^{2}$ in tabular form for the entire range from zero per cent. to one hundred per cent. for the temperature of $20^{\circ}$. An earler table ${ }^{3}$ by $\mathrm{B}$. Wagner comprises the range for ethyl alcohol only from zero to three hundred and thirty, expressed in grams per liter.

The method used by the first-named authors for fixing the concentration of the solutions of which they observed the refraction, is not mentioned in their publication, but the inference is that they deduced the concentrations from density determinations by means of Hehner's tables.

Since, in case of nearly absolute and of very strong alcohol, the refractometer and density constants bear such a relation to one another that the concentration may be much more accurately inferred from the former than from the latter, it follows, that the refraction constants should be fixed independently of observations of specific gravity. For this and other reasons, I decided to prepare absolute alcohol, and from this to make, by dilution with known weights ${ }^{4}$ of water, the solutions needed for the refractometric work.

\section{Preparation of the Absolute Alcohol.}

Three methods came into consideration for the preparation of the absolute alcohol required, viz., the usual quick-lime process; the method of Winkler ${ }^{5}$ with metallic calcium, and the Evans and Fetsch ${ }^{8}$ and Konek

1 Read before the American Chemical Society, January 2, 1908.

2 This Journal, 27, 964 (1905).

${ }^{3}$ Dissertation, Jena (1903).

4 The weighings were not reduced to vacuum.

${ }^{5}$ Ber., 38, 3612 (1905).

- This Journal, 26, I 158 (1904).

7 Ber., 39, 2263 (1 906 ). 